\title{
Use of the Dynamic Simulation to Reduce Handling Complexity in the Manufacturing Process
}

\author{
Vladimíra Schindlerová' ${ }^{*}$, Ivana Šajdlerová ${ }^{1}$ \\ 1 VŠB - Technical University of Ostrava, Faculty of Mechanical Engineering, 17. Listopadu 2172/15, \\ 70833 Ostrava - Poruba, Czech Republic \\ * Correspondding author's e-mail: vladimira.schindlerova@vsb.cz
}

\begin{abstract}
Many companies have started using dynamic simulation as full support for their own optimization team to optimize business processes. The 3D visualization can facilitate understanding of the links among processes and their connections. It can significantly contribute to its appropriate implementation, which aims at saving costs, simplifying processes, introducing new or innovated processes, etc. Application field is not significant for the $3 \mathrm{D}$ visualization. Predictive simulation can be applied in any process, from storage, logistics, handling, through production line optimization to distribution. The submitted paper deals with the optimization of the production process regarding the reduction of handling demands for the company in the automotive industry. Businesses are currently facing an issue of handling complexity, which has a relatively high cost, depending on the amount of unnecessary and chaotic trips within production processes. It is necessary to modify the charging method in any change of production. This is connected with an increase of non-productive rides. The article introduces the possibility of a variant solution with the possibility to use dynamic simulation as a powerful tool for the process optimization.
\end{abstract}

Keywords: simulation, 3D visualization, logistics, optimization

\section{INTRODUCTION}

Over the last 30 years, businesses have undergone significant changes. A lot of them have started using the Lean methodology [7,9]. Most of the methods used for streamlining come mainly from Japan. Among these, there are for example lean, kaizen or six-sigma methods $[2,8]$. Businesses have to learn to respond to their customers' demands very quickly, which can be, and often are, very specific, and which can often change with the environment and market expectations, revising legislation or sustaining society. In conjunction with Industry 4.0, dynamic simulations are being increasingly often used as an effective tool for optimizing a wide range of processes [4, 12]. Especially the automotive industry is an area where the use of simulations already belongs to common practice [5]. The paper presents the possibility of using the simulation in the area of optimization of handling demands in the design of inter-operative transport solutions.

\section{BASIC METHODOLOGY}

The paper deals with optimization of the process, involving handling the material using forklift company in the automotive industry. The aim was to reduce the amount of unproductive trips generated due to the chaotic movement of forklifts in operation using dynamic simulation.

\section{Interoperable transport and material handling}

Interoperable transport and material handling represent a relatively wide area which consists in the entire transfer of raw materials, production stocks and the movement of finished goods 
within the manufacturing plant, including entry and exit storage. The main goal of interoperable transport and the related necessary material handling is to ensure the smoothest possible flow of material and to achieve a continuous manufacturing process [11].

In order to determine the material handling complexity of forklifts, it was essential to establish a database. The basic elements of the database are:

- its own system observation and timing,

- determination of the distance matrix,

- vehicle fleet identification.

\section{Dynamic simulation}

Simulation modelling involves model development which imitates real-world operations, statistical analyses and their performance with the aim to improve efficiency and effectiveness. The term simulation denotes creating accurate models which represent real-world systems and allow us to experiment at the level of debugging and replenishing models within the simulation. Thus, we can ask "what if" questions that have to be answered without any risk of disruption of the real system. The simulation principle is simple - to copy the operation of a real business system by means of a computer simulation and then to monitor the system behaviour during various experiments and testing of different variants (Figure 1). An example of such a model system may be a production line, storage space, information flow in the enterprise, etc. [3]

In practice, applications have shown that the use of simulation can be widely used not only for business processes but also in such areas as transport simulation, where financial, material and personnel savings can be achieved. $[4,6,10]$.

\section{A CASE STUDY ON THE APPLICATION OF DYNAMIC SIMULATION IN PRACTICE}

The case study concerns optimization of the material handling process by using forklifts in an automotive business. The enterprise is a medium-sized company with 125 employees. The aim was to reduce the number of non-productive rides which arise from the chaotic movement of handlers.

\section{Input data}

The analysis of the current state involves determination of a database which includes the manipulated material volumes over a one month period. An overview of the manipulated pallet volume is stated in Figure 2 [1].

Five forklifts owned by the company were involved in this total number of pallets transported. Each of these pallets represents one requirement for the material handling which had to be transferred from the place of loading to the place of unloading given by the process.

Another element of the database is the determination of the handling points where the loading operations take place. Placed upon the production hall layout, 46 manipulation points were identified (Figure 3). The matrix of distances between the handling locations was determined based on this background.

The last element of the database is the determination of the frequency of material handling needs. The longest handling time is over an hour, the shortest span is 0 seconds. The average value between the handling needs is less than 10 minutes. The current handling equipment capacity is 5 forklifts. It was necessary to determine the present state of distances for the productive and

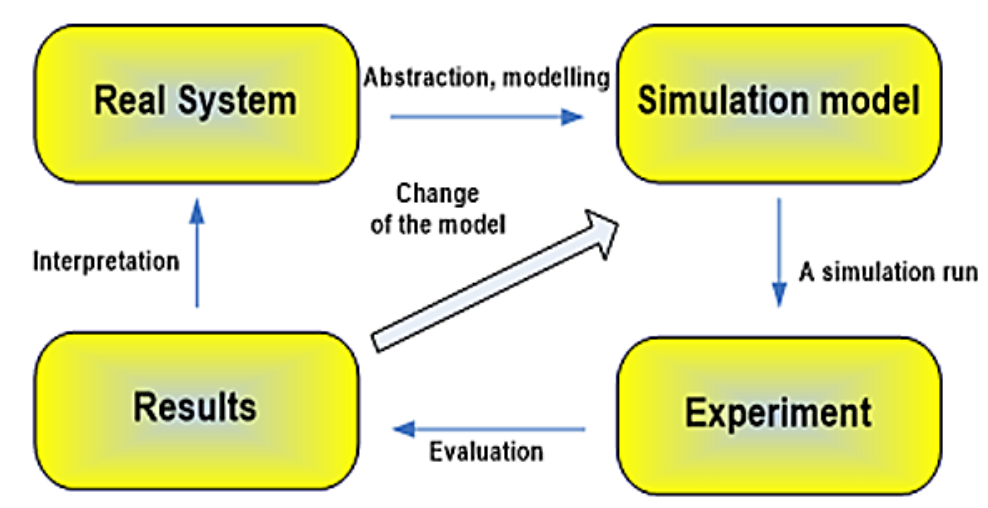

Fig. 1. Principle of the simulation [3] 


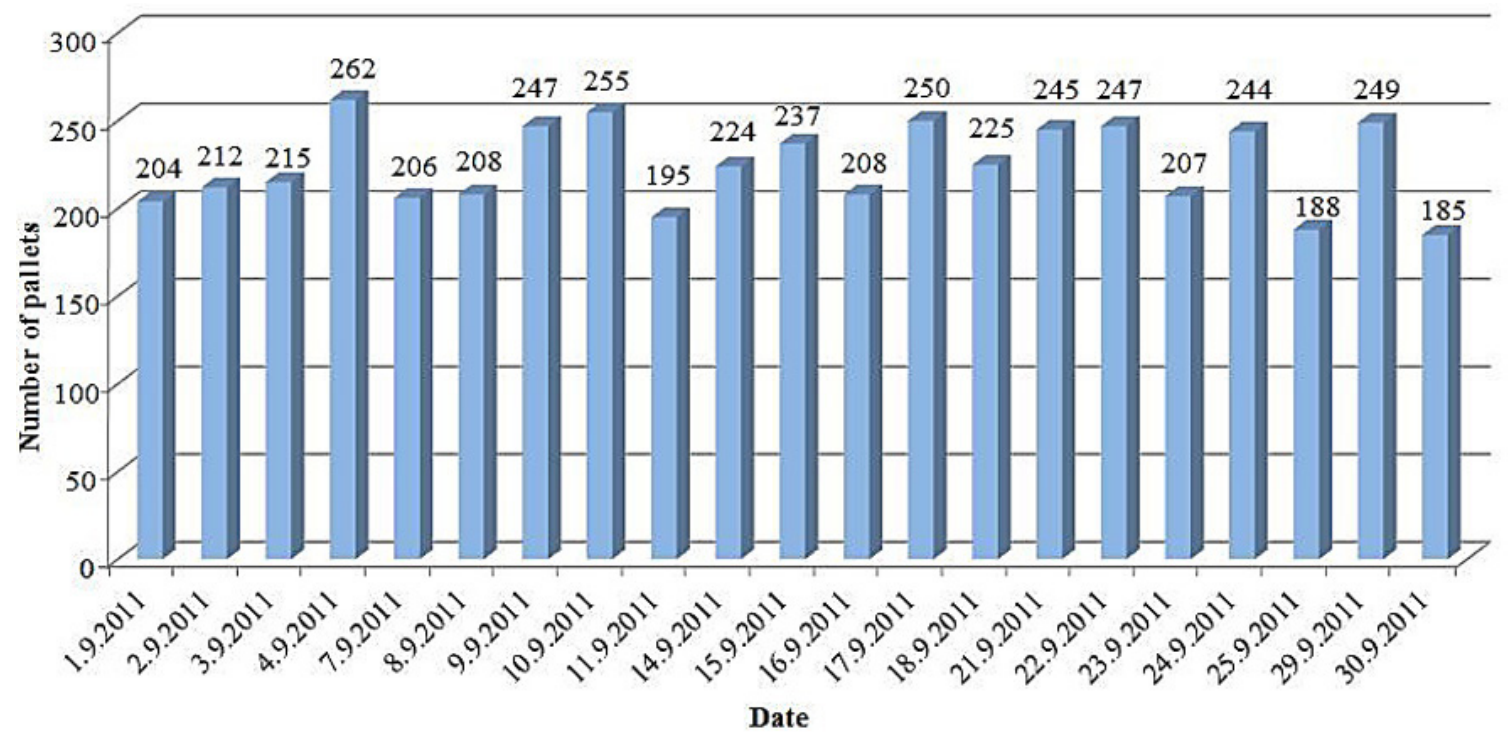

Fig. 2. Overview of the manipulated pallet volume [1]

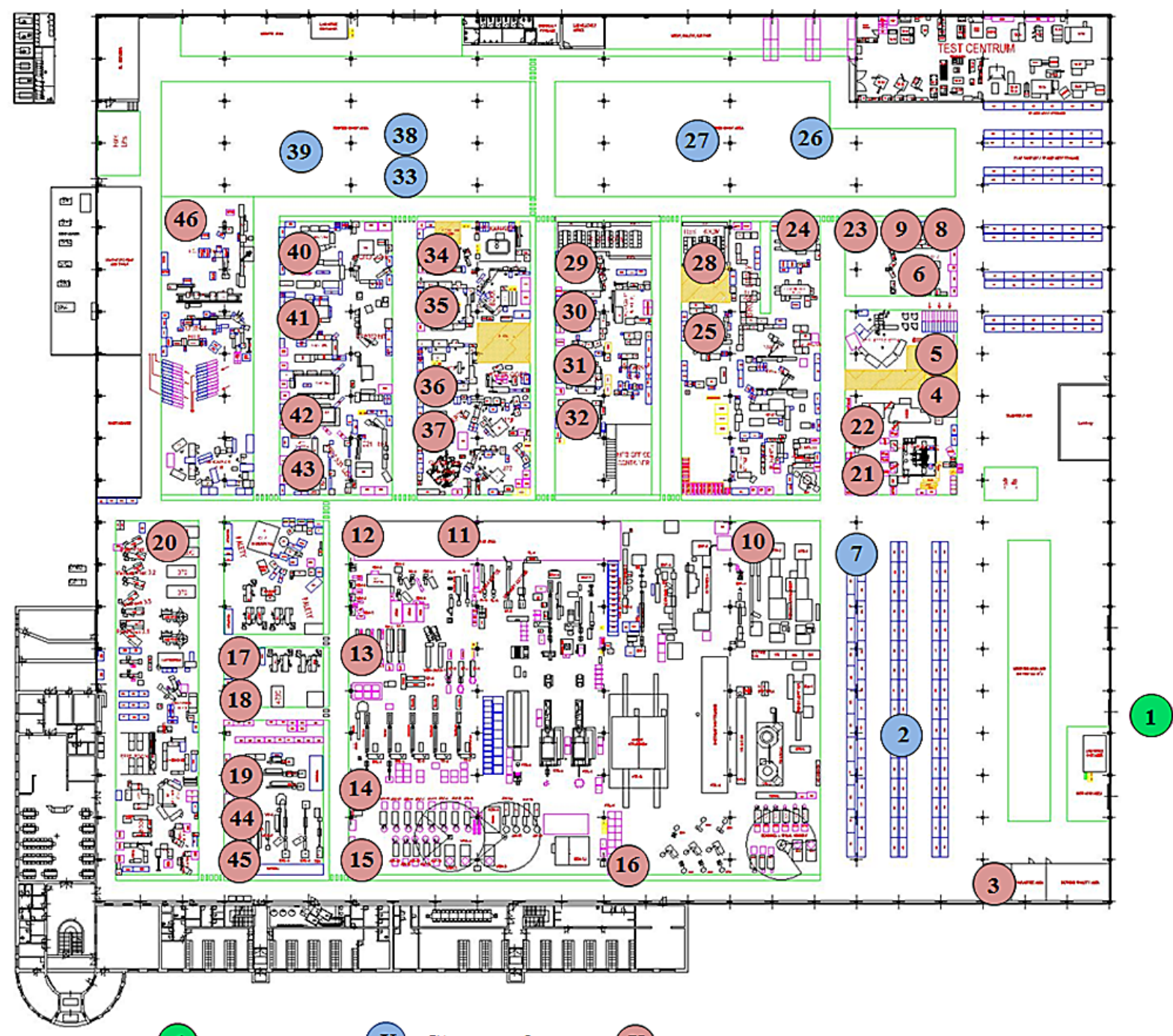

(1) Depot VZV (x) Storage places (X) Production lines

Fig. 3. Identification of the manipulation points in the layout [1] 
non-productive rides over the reference period (Table 1). The principle of defining the productive and non-productive rides is shown in the figure (Figure 4) [1]. An important piece of information regarding the forklifts is the cost of their work hours. An overview of the work hours and their conversion to costs is given in Table 2 .

The simulation of the assigned problem was carried out using the Witness software. The primary data were acquired in the company and had to be adjusted for the simulation requirements so that the simulation system was easier to set up. An example of primary and modified data is shown in Table 3.

The linking of the Witness and Excel data is shown in Figure 5. The input data are based on a distance matrix which determines the distance of particular manipulation points. A work algorithm has been defined to guide the forklift operator. The core of the solution consists in the fastest possible serving of the material handling requirement. There are 5 forklifts available. The decision-making process is based on an algorithm that is defined in such a way that when a new request is entered, the forklift that can handle the request in the shortest possible time is selected.

The simulation model was developed on the basis of riding circuits for all the handling equipment owned by the company. Loading and unloading in the model is represented by the paths on which the forklifts stay for a set period of time. This results from the measurements in operation. At the first request, the forklift leaves the depot and sets out for loading, which has a length according to the distance matrix, then the loading follows. After the loading time, it goes on to the unloading, the length of which is again found in the distance matrix. After unloading, the forklift

Table 1. Odometer in the current state [1]

\begin{tabular}{|c|c|}
\hline Breakdown of distances & Current state $[\mathrm{m}]$ \\
\hline Productive rides & 303726 \\
\hline Non-productive rides & 420902 \\
\hline Total distance & 724628 \\
\hline
\end{tabular}

remains at the end of the loading route and waits for the next request. Once the request is assigned, it sets out for the loading again (Figure 6) [1].

\section{Evaluation of simulation experiments and results}

Two solutions were designed and simulated. The first solution concerned handling the request in the shortest possible time by a forklift which can carry it out as soon as possible. The graphical representation of the achieved results is shown in Figure 7. It shows that the savings occurred not only in the travelled distance, but also in the saved time. An important comparison of the current state and the proposed variant is the financial savings in the monitored period. Reducing the non-productive rides can save CZK 826, which includes fuel savings equivalent to a total of 22.9 litres [1].

The other solution dealt with the number of forklifts necessary to meet the requests. The result of this solution was to recommend the optimal number of forklifts for the business. The Optimizer tool which enables to search for the optimal solution to complex problems in a simple way was used. A solution to track the changes in the modified number of forklifts from one to ten devices has been proposed. Table 4 shows the savings when comparing the original state with the simulation results. It is obvious that as the number of forklifts increases not only the savings in the travelled distance, but also the time and financial costs associated with the forklifts are reflected [11].

The results of the above-mentioned solutions offer possible savings in the reduction of non-productive rides, which is only CZK 826 per month when using 5 forklifts.

With five forklifts, the workload is only $3.1 \%$, while the operator waits for the next handling requirement for the rest of the time. If the company uses one forklift only, the savings are much more interesting: this would increase the workload to $15.9 \%$. The other forklift would serve as a

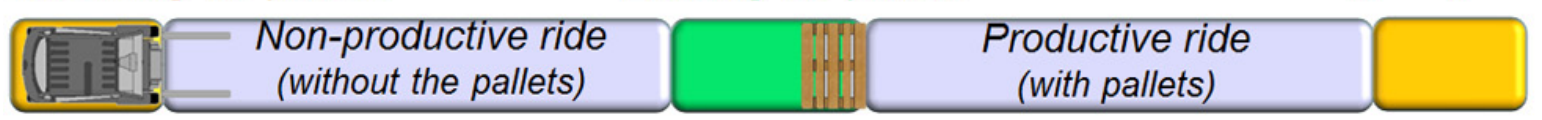

Fig. 4. Scheme of non-productive and productive rides [1] 
Table 2. Costs per work hour at current state [1]

\begin{tabular}{|c|c|c|}
\hline Breakdown of times & Number of work hours [h] & Costs per work hour [Kč] \\
\hline Productive rides & $52: 44$ & 3987 \\
\hline Non-productive rides & $48: 43$ & 3683 \\
\hline Loading the pallets & $10: 08$ & 766 \\
\hline Unloading the pallets & $11: 03$ & 835 \\
\hline Total time & $122: 38$ & 9271 \\
\hline
\end{tabular}

Table 3. Primary and modified model input data [1]

\begin{tabular}{|c|c|c|c|c|c|c|c|}
\hline Date & From & To & Article & Time $[\mathrm{min}]$ & From & To & ID_article \\
\hline $\begin{array}{c}1.9 .2011 \\
1: 10: 40\end{array}$ & KB58/VG9 & D207 & 6071083.06 AND & 0 & 37 & 39 & 169 \\
\hline $\begin{array}{c}1.9 .2011 \\
2: 27: 00\end{array}$ & KB58/VG9 & D207 & 6055043 R01.023C & 86 & 37 & 39 & 126 \\
\hline $\begin{array}{c}1.9 .2011 \\
2: 47: 50\end{array}$ & KPQ35EHS & D043 & 6540209 R00.00 & 97 & 28 & 26 & 200 \\
\hline $\begin{array}{c}1.9 .2011 \\
2: 55: 59\end{array}$ & KC170/C3 & E333 & $9613540 . E$ & 105 & 36 & 38 & 251 \\
\hline $\begin{array}{c}1.9 .2011 \\
3: 00: 51\end{array}$ & KAUDI & D207 & 6604052 R01.04 & 110 & 30 & 39 & 216 \\
\hline
\end{tabular}

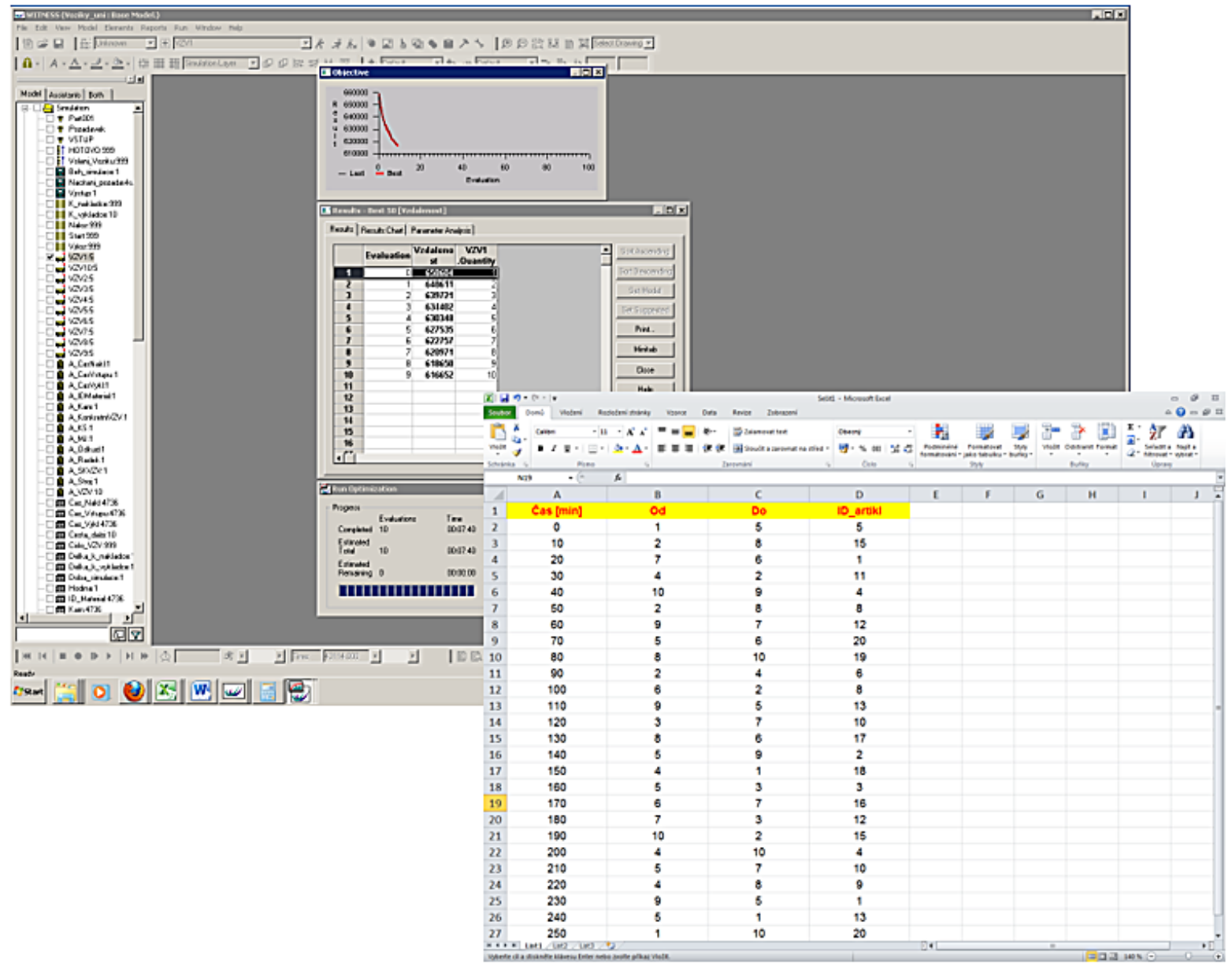

Fig. 5. Witness window and Excel workbook [1] (only illustrative picture) 


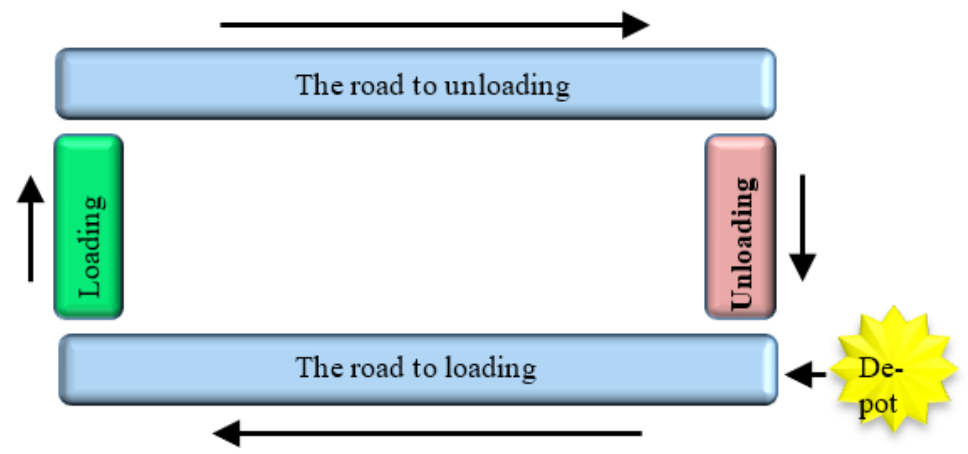

Fig. 6. The principle of riding circuits of the forklifts [1]
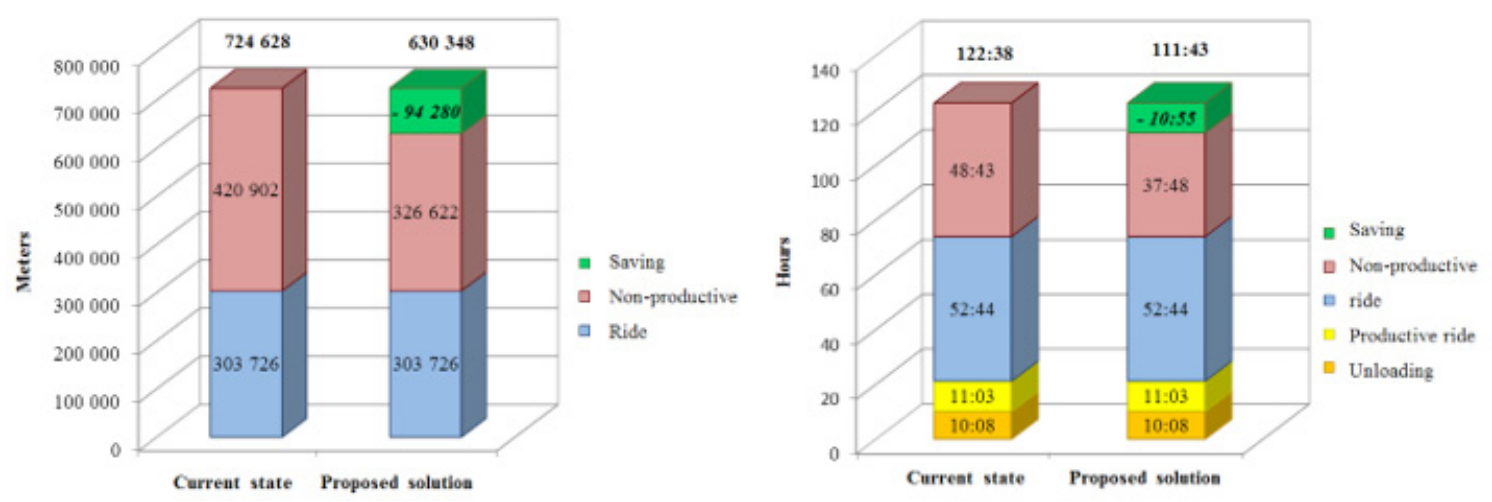

Fig. 7. Comparison of the original state and the new solution [1]

Table 4. Comparison of the original state and the new solution [1]

\begin{tabular}{|c|c|c|c|c|c|c|c|c|c|c|}
\hline & $\begin{array}{c}\text { Number } \\
\text { for forklifts }\end{array}$ & $\begin{array}{l}\text { Productive ride } \\
{[\mathrm{m}]}\end{array}$ & $\begin{array}{c}\text { Non-productive ride } \\
{[\mathrm{m}]}\end{array}$ & $\begin{array}{c}\text { Total distance } \\
{[\mathrm{m}]}\end{array}$ & $\begin{array}{l}\text { Savings } \\
{[\mathrm{m}]}\end{array}$ & & $\begin{array}{l}\text { Number for } \\
\text { forklifts }\end{array}$ & $\begin{array}{l}\text { Mth total } \\
\text { [hhh:mm] }\end{array}$ & Financial costs [Kě] & $\begin{array}{c}\text { Savings } \\
\text { [Kěc] }\end{array}$ \\
\hline Current state & 5 & 303726 & 420902 & 724628 & - & Current state & 5 & $122: 38$ & 9271 & - \\
\hline \multirow{10}{*}{$\begin{array}{l}\text { Simulation } \\
\text { results for the } \\
\text { given number } \\
\text { of forklifts }\end{array}$} & 1 & 303726 & 354878 & 658604 & 66024 & \multirow{10}{*}{$\begin{array}{l}\text { Simulation } \\
\text { results for the } \\
\text { given number } \\
\text { of forklifts }\end{array}$} & 1 & $114: 59$ & 8693 & 578 \\
\hline & 2 & 303726 & 344885 & 648611 & 76017 & & 2 & 113:50 & 8605 & 666 \\
\hline & 3 & 303726 & 335995 & 639721 & 84907 & & 3 & $112: 48$ & 8528 & 743 \\
\hline & 4 & 303726 & 330676 & 634402 & 90226 & & 4 & 112:11 & 8481 & 790 \\
\hline & 5 & 303726 & 326622 & 630384 & 94280 & & 5 & $111: 43$ & 8445 & 826 \\
\hline & 6 & 303726 & 323809 & 627535 & 97093 & & 6 & $111: 24$ & 8421 & 850 \\
\hline & 7 & 303726 & 319031 & 622757 & 101871 & & 7 & $110: 50$ & 8379 & 892 \\
\hline & 8 & 303726 & 317245 & 620971 & 103657 & & 8 & $110: 38$ & 8364 & 907 \\
\hline & 9 & 303726 & 314924 & 618650 & 105978 & & 9 & $110: 22$ & 8343 & 928 \\
\hline & 10 & 303726 & 312926 & 616652 & 107976 & & 10 & $110: 08$ & 8326 & 945 \\
\hline
\end{tabular}

back-up in the event of a major overhaul or breakdown (Figure 8) [1].

On the basis of this result, the company can be recommended to reduce the number of working forklifts to one that can meet all handling requirements without any problems. The comparison of costs is shown in Table 5.

The results of the executed simulations and the drawn conclusions confirm what the company managers suspected intuitively. The disorganized movement of five not fully loaded forklifts led to many non-productive rides. The rides did not often arise from the real operational needs, but from the needs of the operator to fill the working hours with some work. Therefore, it is obvious why the company felt the need to bring a work system into the movement of the forklift operators in the plant.

One way of implementing the suggested work system is to use an on-line forklift terminal. With the purchase of the terminal, it is also necessary to establish a radio network in the plant. 


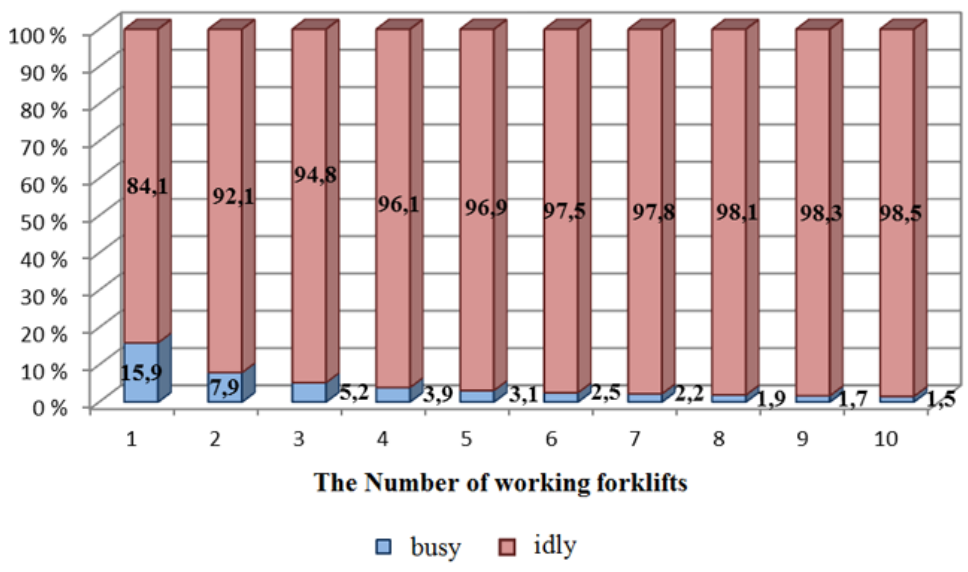

Fig. 8. Forklift workload in \% [1]

Tab. 5. Comparison of costs for one and five forklifts [1]

\begin{tabular}{|l|c|c|}
\hline \multirow{2}{*}{\multicolumn{1}{|c|}{ Type of costs }} & \multicolumn{2}{c|}{ Annual costs [Kč] } \\
\cline { 2 - 3 } & 1 forklift & 5 forklifts \\
\hline Regular repairs & 4500 & 22500 \\
\hline Medium-scale repairs & 18000 & 90000 \\
\hline Overhaul & 55000 & 641666 \\
\hline Technical inspection & 1000 & 5000 \\
\hline $\begin{array}{l}\text { Fuel consumption per Mth } \\
\text { (working hour) }\end{array}$ & 104316 & 101340 \\
\hline Tire wear & 5519 & 5362 \\
\hline Other maitenance & 9000 & 45000 \\
\hline Forklift driver & 180000 & 900000 \\
\hline Average coasts & 377335 & 1810868 \\
\hline Savings & $\mathbf{1 4 3 3 5 3 3}$ & \\
\hline
\end{tabular}

\section{CONCLUSIONS}

The paper presents the findings regarding the field of manipulation and use of dynamic simulation, which is a powerful tool in the optimization of production processes. The aim of the simulation was to introduce the system into the movement of forklifts in the plant and thus reduce the overall handling effort.

Numerous businesses are currently facing the problem with the low workload of material handling operators. Manipulators working in the company usually find their own system they follow. However, when the manufacturing process changes, their movement becomes disorganized and chaotic.

The suggested solution should help the company to better organize the work and to use the created algorithm even for the changes that may occur in the manufacturing system.

\section{REFERENCES}

1. Cajzlová D. Production proces optimalization by the means of reducing manipulation demands. Master thesis. Vysoká škola báňská - Technická univerzita Ostrava. Ostrava 2012, Czech Republic.

2. Cierna, H. and Sujova E. Application of modern QMS - Kaizen management system. MM Science Journal, November 2016, 1456-1464.

3. Dlouhý, M. Simulace podnikových procesů. Computer Press, 2007.

4. Fedorko G., Neradilová H. and Jackanin J. Discrete model simulation of a passenger cable car operation. Advances in Science and Technology Research Journal, 12(2), 2018, 170-179.

5. Krolczyk J.B , Krolczyk G.M., Legutko S., Napiorkowski J., Hloch S., Foltys J. and Tama E. Material flow optimization - a case study in automotive industry. Technicki Vjestnik, 22(6), 2015, 1447-1456.

6. Law A.M. Simulation modeling and analysis. McGraw-Hill, 2007.

7. Liker J.K. The Toyota Way: 14 Management Principles from the World's Greatest Manufacturer. McGraw-Hill, 2014.

8. Méndez J.D.M. and Rodriguez R.S. Total productive maintenance (TPM) as a tool for improving productivity: a case study of application in the bottleneck of an auto-parts machining line. The International Journal of Advanced Manufacturing Technology, 92(1-4), 2017, 1013-1026.

9. Patel A.B. and Desai T.N. A systematic review and meta-analysis of recent developments in sustainable supply chain management. International Journal of Logistics Research and Applications, 22(4), 2019, 349-370.

10. Schindlerová V., Šajdlerová I. and Mohyla P. Optimization of metallurgical processes using dynamic simulation, Proc. of METAL 2016 - 25th Anniversary International Conference on Metallurgy and 
Materials, Brno, Czech Republic 2016, 2013-2018.

11. Schindlerová V. and Šajdlerová I. Influence of tool wear on material flow. Advances in Science and Technology Research Journal, 11(1) 2017, 161-165.
12. Worobel R, Čapek J., Kováčová L., Bubeník P. and Krajcovič M. Improving business processes using simulation tools. MM Science Journal, March 2018, 2244-2251. 